\title{
Where to with the Plastic Straws?
}

\author{
Researchers from Brazil introduced a new application for reusing plastic straws: They \\ produced fibers from recycled plastic straws that can be used as additives for refractory \\ materials. These fibers make the drying of refractory products safer and faster.
}

In the past decades, human beings consumed approximately 9 billion plastic beverage straws per day and most of them ended up in the oceans along with 5 to 10 million tons of other types of plastic wastes dumped every year. Due to their floatability, they can spread over the oceans after a few months. Because of the deleterious environmental impact on aquatic life, many cities banned or plan to ban their use in restaurants and other public spaces.

Straws are typically made of isotactic polypropylene (PP) or high-density polyethylene (HDPE) and their recycling is tricky due to the difficulties found in selective pickup and the thermal degradation these polymers present after a second processing

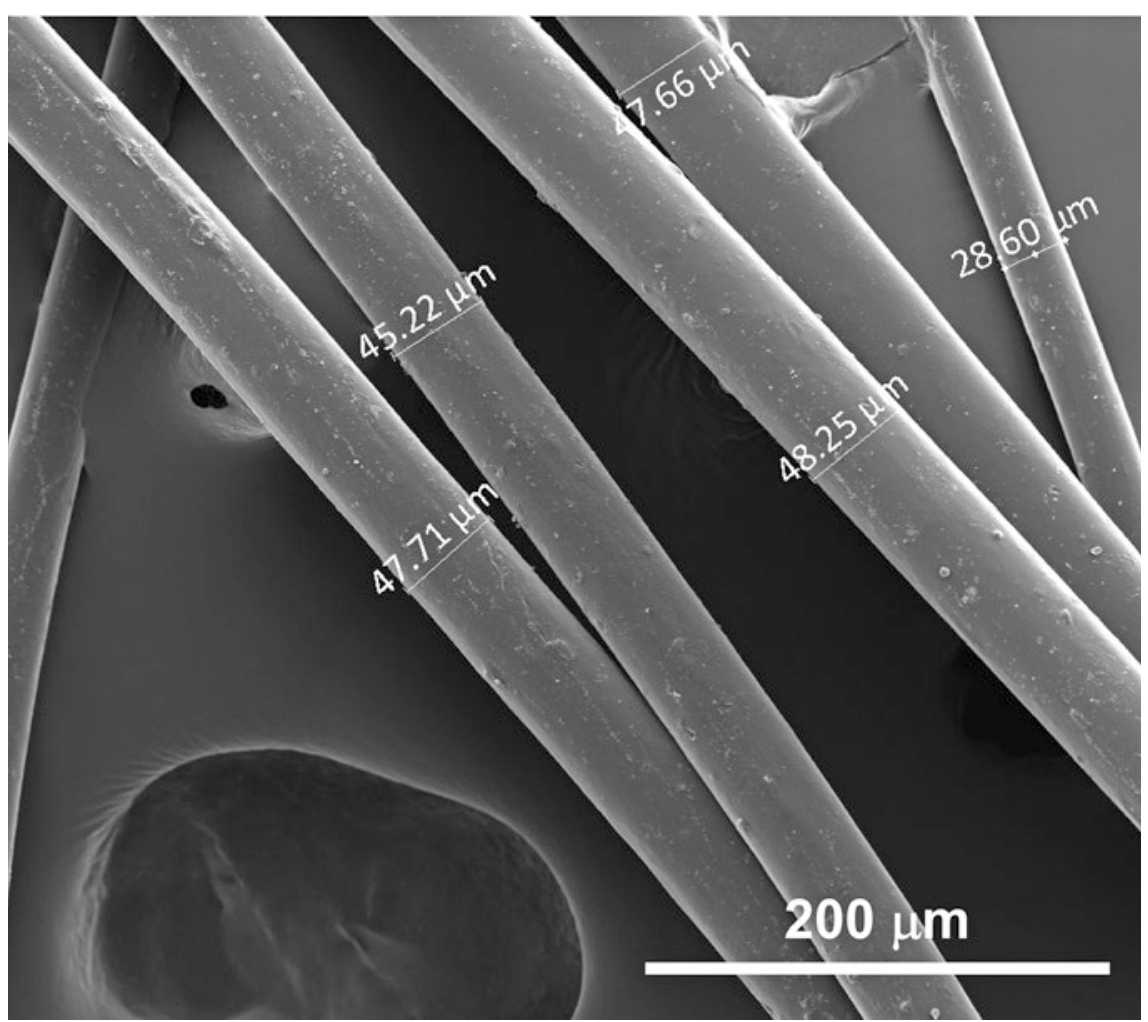

Figure 1 Fibers produced from recycled polypropylene straws (৫ Salomão) cycle. As a consequence, recycled straws can not be used to produce new ones. However, a recent work proposed a novel application for these materials.

Researchers from Brazil from the Federal University of São Carlos and São Carlos School of Engineering used recycled straws to melt-spun thin continuous fibers that were chopped into $3 \mathrm{~mm}$ staples and mixed with a high-alumina self-flowing refractory castable formulation. After hardening and during the initial heating of the casted parts, the recycled-straw fibers melt and form permeable canals throughout the structure of the refractory, easing the release of water vapor. Known as anti-spalling additives, these fibers significantly reduce the required

\section{Original Publication}

R. Salomão, V.C. Pandolfelli, "Anti-spalling fibers for refractory castables: A potential application for recycling drinking straws", Ceramics International (In press) (2020). doi.org/10.1016/j.ceramint.2020.02.122

time and the consumption of energy to heat-up the refractory linings and prevent explosive spalling caused by pressurized water vapor.

The recycled fibers (Figure 1) have a significantly lower melting point (approximately $141^{\circ} \mathrm{C}$ ) in comparison to the conventional fibers used in this application (170$180^{\circ} \mathrm{C}$ ). Due to this, they are more efficient in reducing water vapor pressurization, allowing a safer installation with smaller consumption of fuel for heating and fewer maintenance time.

Besides being an alternative for the destination of straws and improving the refractory castables drying behavior, these fibers can also be added to construction concrete to prevent explosions in fire situations based on the same principles. Because these concretes are produced in a much larger volume than refractory castables, other types of plastic wastes could also be employed to produce recycled fibers.

Contact:

Prof. Dr. Rafael Salomão, Materials Engineering Department (SMM), São Carlos School of Engineering (EESC), University of São Paulo (USP), Brazil, www.sites.google.com/site/rflslm 